\title{
Perioperative detection of circulating tumour cells in patients with lung cancer
}

\author{
DIMPLE CHUDASAMA ${ }^{1,3}$, NATHAN BURNSIDE ${ }^{1}$, JULIE BEESON $^{1}$, \\ EMMANOUIL KARTERIS ${ }^{3}$, ALEXANDRA RICE ${ }^{2}$ and VLADIMIR ANIKIN ${ }^{1}$
}

\begin{abstract}
Departments of ${ }^{1}$ Cardiothoracic Surgery and ${ }^{2}$ Pathology, Harefield Hospital, Royal Brompton and Harefield Trust, Harefield, Middlesex UB9 6JH; ${ }^{3}$ Department of Life Sciences, Brunel University London, Uxbridge, Middlesex UB8 3PH, UK
\end{abstract}

Received July 28, 2016; Accepted November 30, 2016

DOI: $10.3892 / 01.2017 .6366$

\begin{abstract}
Lung cancer is a leading cause of mortality and despite surgical resection a proportion of patients may develop metastatic spread. The detection of circulating tumour cells (CTCs) may allow for improved prediction of metastatic spread and survival. The current study evaluates the efficacy of the ScreenCell ${ }^{\circledR}$ filtration device, to capture, isolate and propagate CTCs in patients with primary lung cancer. Prior to assessment of CTCs, the present study detected cancer cells in a proof-of-principle- experiment using A549 human lung carcinoma cells as a model. Ten patients (five males and five females) with pathologically diagnosed primary non-small cell lung cancer undergoing surgical resection, had their blood tested for CTCs. Samples were taken from a peripheral vessel at the baseline, from the pulmonary vein draining the lobe containing the tumour immediately prior to division, a further central sample was taken following completion of the resection, and a final peripheral sample was taken three days post-resection. A significant increase in CTCs was observed from baseline levels following lung manipulation. No association was able to be made between increased levels of circulating tumour cells and survival or the development of metastatic deposits. Manipulation of the lung during surgical resection for non-small cell lung carcinoma results in a temporarily increased level of CTCs; however, no clinical impact for this increase was observed. Overall, the study suggests the ScreenCell ${ }^{\circledR}$ device has the potential to be used as a CTC isolation tool, following further work, adaptations and improvements to the technology and validation of results.
\end{abstract}

Correspondence to: $\mathrm{Dr}$ Nathan Burnside, Department of Cardiothoracic Surgery, Harefield Hospital, Royal Brompton and Harefield Trust, Hill End Road, Harefield, Middlesex UB9 6JH, UK E-mail:n.burnside@rbht.nhs.uk

Key words: circulating tumour cells, lung cancer, diagnosis

\section{Introduction}

Lung cancer continues to be a leading cause of mortality in the western world (1). The primary cause of mortality even following successful resection of the primary tumour is metastatic spread $(1,2)$. One major route for lung cancer metastatic spread is the movement of displaced cells through the circulation to distant sites (3). Circulating tumour cells (CTCs) are cells that shed from the primary tumour and have been detected in the peripheral blood of patients with cancer. Previous studies have revealed that CTCs are heavily implicated in metastatic spread $(3,4)$. Understanding CTC biology has become a fundamental part of cancer research, as diagnostic blood assays for cancer are an area of growing interest. A number of studies have presented evidence of the utility of CTCs as potential cancer biomarkers for diagnostic and prognostic purposes, which may serve as a minimally invasive 'liquid biopsy' for real-time diagnosis (5-7). Therefore, the ability to isolate and evaluate these CTCs may allow for a new method of cancer staging and to predict which patients may exhibit an improved response to systemic treatments as opposed to surgical excision alone.

Although blood to the lungs is supplied by the pulmonary and bronchial arteries, the bronchial veins account for very little venous drainage, with almost all blood returning to the heart through the pulmonary veins. This single route for venous drainage provides an excellent model for the assessment of CTCs, through sampling blood returning from the tumour-bearing lobe to the main circulation. Despite being a naturally effective model for the study of CTCs, little is known regarding the presence of CTCs in the blood draining from the tumour-bearing lobe and their long-term impact on survival.

The aim of the current study was to quantify the concentration of CTCs in blood obtained from the pulmonary vein and from simultaneously assessed peripheral blood in patients with detectable lung cancer. Other goals of the present study were to determine the association between CTC detection and cancer stage, histology, lung manipulation and other clinical parameters.

\section{Materials and methods}

Cell culture. A549 human lung carcinoma cells (American Type Culture Collection, Manassas, VA, USA) were grown 
in advanced Dulbecco's modified Eagle's medium (DMEM) containing high glucose, non-essential amino acids, sodium pyruvate, phenol red and no L-glutamine (Gibco; Thermo Fisher Scientific, Inc., Waltham, MA, USA). The advanced DMEM was further supplemented with $1 \%(\mathrm{v} / \mathrm{v})$ penicillin and streptomycin solution (Invitrogen; Thermo Fisher Scientific, Inc.) and 10\% (v/v) foetal bovine serum (Invitrogen; Thermo Fisher Scientific, Inc.). All cell cultures were maintained in a humidified atmosphere in an incubator at $37^{\circ} \mathrm{C}$ containing $5 \% \mathrm{CO}_{2}$, with media being changed every $48 \mathrm{~h}$ to ensure optimal growth.

Patients. Ethical approval was sought and granted for the present study from the National Research Ethics Service, now the Health Research Authority (reference no. 14/LO/1284). Patients awaiting radical resection of primary non-small cell carcinoma of the lung were recruited from Harefield Hospital (Royal Brompton and Harefield Trust, Middlesex, UK) following informed consent.

Ten patients aged between 50 and 84 years old (mean age, 64 years old) were enrolled between November 2014 and June 2015. Five patients were male and five were female. Seven patients had a history of heavy cigarette smoking, with three having never smoked. Two patients had known, although minimal, previous asbestos exposure. No patients had received therapeutic or neoadjuvant oncological treatments prior to surgery for lung cancer. Between the patients, five tumours were located in the right lung (two upper lobe, one middle lobe, 2 lower lobe) and five in the left ( 3 upper lobe, two lower lobe). Eight tumours were identified as adenocarcinomas and two as squamous cell carcinomas. Tumours were resected at various stages, with three staged at Ia, two at Ib, one at IIa, three at IIb and one at IIIa. No patients had detectable distant metastatic disease at resection. Nine patients underwent a pulmonary lobectomy, with two procedures performed thoracoscopically. One patient underwent a planned pneumonectomy. In all cases the pulmonary vein was ligated prior to division of pulmonary artery branches or bronchus.

All blood samples were taken in the operating theatre after the patient was anaesthetised and the process is illustrated in Fig. 1. Briefly, the baseline sample was taken from a peripheral vein or artery prior to the incision. Following intraoperative assessment of surgical resectability, a second sample was collected from the pulmonary vein draining the lobe-bearing tumour prior to the surgical division of the pulmonary vein. When the planned surgical intervention with systematic lymph dissection was completed, a third sample was collected from the pulmonary vein stump. A final sample was obtained three days postoperatively from the peripheral vein, together with routine clinical blood sampling.

Processing of blood samples using ScreenCell ${ }^{\circledR}$. ScreenCell ${ }^{\circledR}$ filtration device technology (ScreenCell, Paris, France) was utilised as previously described (1). Blood sample processing is illustrated in Fig. 1. Briefly, all blood samples were collected in $3 \mathrm{ml}$ EDTA bottles, inverted, incubated in $7 \mathrm{ml}$ of fixative buffer (ScreenCell, Paris, France) and then filtered through the Cytology ScreenCell ${ }^{\circledR}$ device. Filters were then separated and captured cells stained with haematoxylin and eosin (H\&E). All H\&E stained slides were then viewed by a consultant pathologist and cells manually counted with a microscope and documented.

Immuocytochemistry analysis of A549 human lung carcinoma cells. A549 human lung carcinoma cells (America Type Culture Collection, Manassas, VA, USA) were grown in T75 flasks to $90 \%$ confluency. For this proof-of-principle experiment, $\sim 50$ A549 cells were inoculated into either $3 \mathrm{ml}$ of blood from a healthy volunteer or $3 \mathrm{ml}$ of PBS solution with lymphocytes added. In the latter case, 50 lymphocytes were taken from healthy volunteer blood by means of density gradient centrifugation. A549 cells were collected using the Countess Automated Cell Counter (Invitrogen; Thermo Fisher Scientific, Inc.) and stained with trypan blue (Invitrogen; Thermo Fisher Scientific, Inc.). Media was aspirated from the cells in the flask, which were then incubated with $2 \mathrm{ml}$ of TrypLE ${ }^{\mathrm{TM}}$ Express (Invitrogen; Thermo Fisher Scientific, Inc.) and manually agitated. The cells were resuspended in $3 \mathrm{ml}$ of appropriate media to produce a $5 \mathrm{ml}$ cell suspension, of which $1 \mathrm{ml}$ was removed. An equal volume of cell suspension was mixed with $0.4 \%$ trypan blue stain, which is selectively absorbed by dead cells, and applied to a Countess ${ }^{\mathrm{TM}}$ cell counting chamber slide. Three cell count readings were obtained and an average value calculated. Approximately 50 cells were then added to PBS or human blood. The appropriate volume of cells was washed with $5 \mathrm{ml}$ of PBS (Invitrogen; Thermo Fisher Scientific, Inc., Waltham, MA, USA), and then treated with $4 \%$ paraformaldehyde on ice for $3 \mathrm{~min}$. The primary antibody used was a monoclonal mouse anti-human cytokeratin AE1/3 clone (catalogue no., M351529-2; Dako; Agilent Technologies, Inc., Santa Clara, CA, USA). A 1:50 dilution was prepared, as instructed by the ScreenCell ${ }^{\circledR}$ protocol. The antibody was diluted in a solution of Tris-buffered saline (TBS) and $1 \%$ bovine serum albumin (Invitrogen; Thermo Fisher Scientific, Inc.), and $70 \mu \mathrm{l}$ of antibody solution was added to each filter at $4^{\circ} \mathrm{C}$ overnight. Following primary antibody incubation, the filters were washed twice for $1 \mathrm{~min}$ in TBST (1:10 dilution of Tween-20:TBS). Excess liquid was blotted and the filters were returned to the humidifying chamber on slides with $70 \mu 1$ of horseradish peroxidase (HRP)-conjugated biotinylated anti-mouse secondary antibody at a 1:1,000 dilution (catalogue no., K4065; Dako EnVision+ kit; Agilent Technologies, Inc.) for $40 \mathrm{~min}$ at room temperature. Following secondary antibody incubation, filters were washed twice for $1 \mathrm{~min}$ in TBST, and excess liquid blotted off. A 3,3'-diaminobenzidine (DAB) -chromogen solution was mixed (20 $\mu 1$ of DAB to $1 \mathrm{ml}$ of DAB solution; Dako EnVision+ kit) and $70 \mu 1$ of the solution was added to each filter prior to incubation for $10 \mathrm{~min}$ at room temperature in the humidifying chamber. This was followed by the washing of filters in distilled water for $1 \mathrm{~min}$. The filters were then placed on Whatman paper and allowed to dry at room temperature for $15 \mathrm{~min}$ prior to light microscopy of positively stained cancer cells.

Statistical analysis. Captured data was analysed using GraphPad prism version 5 (San Diego, CA, USA) with significance set at $\mathrm{P}<0.05$. 


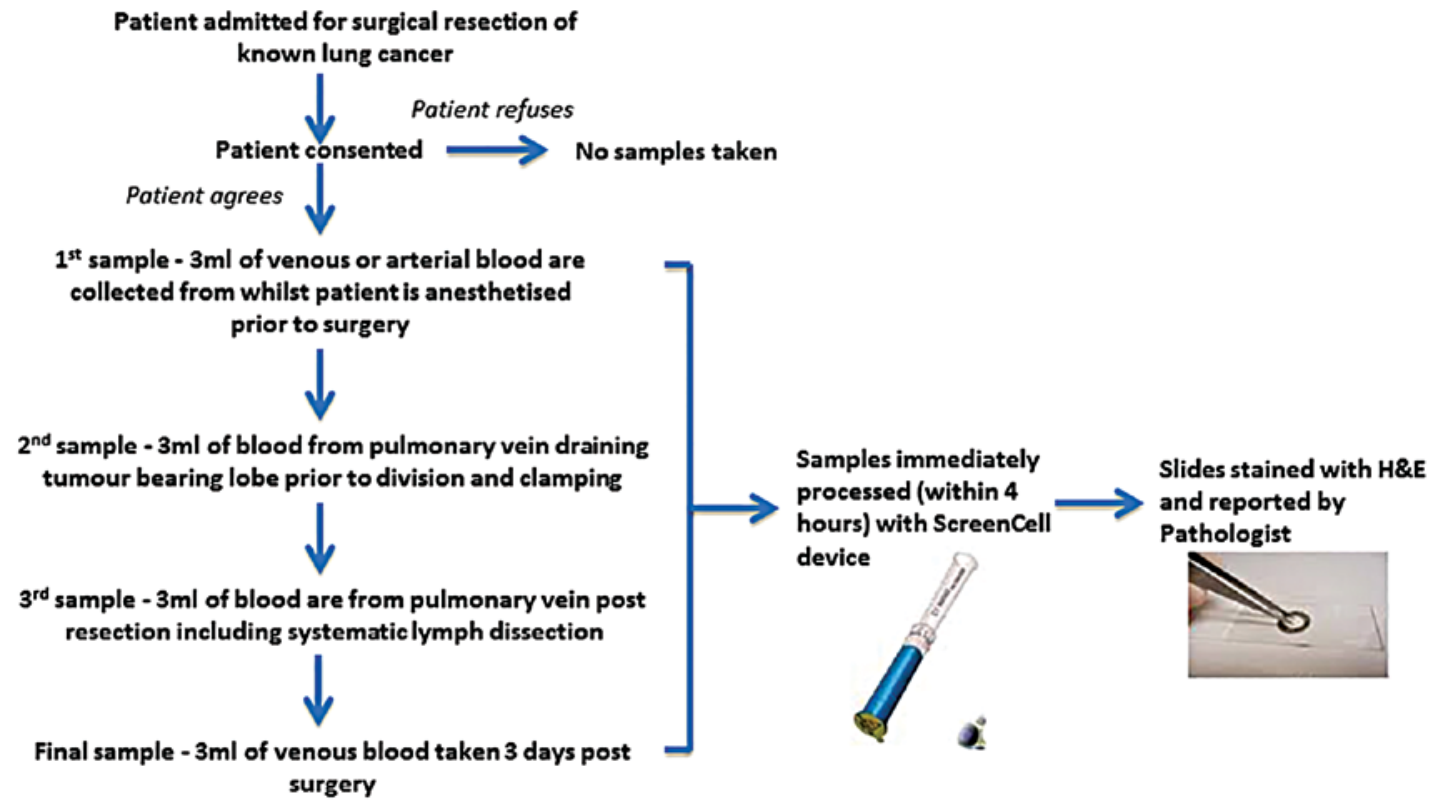

Figure 1. Flow diagram of the blood sample collection and staining process used. H\&E, haematoxylin and eosin.

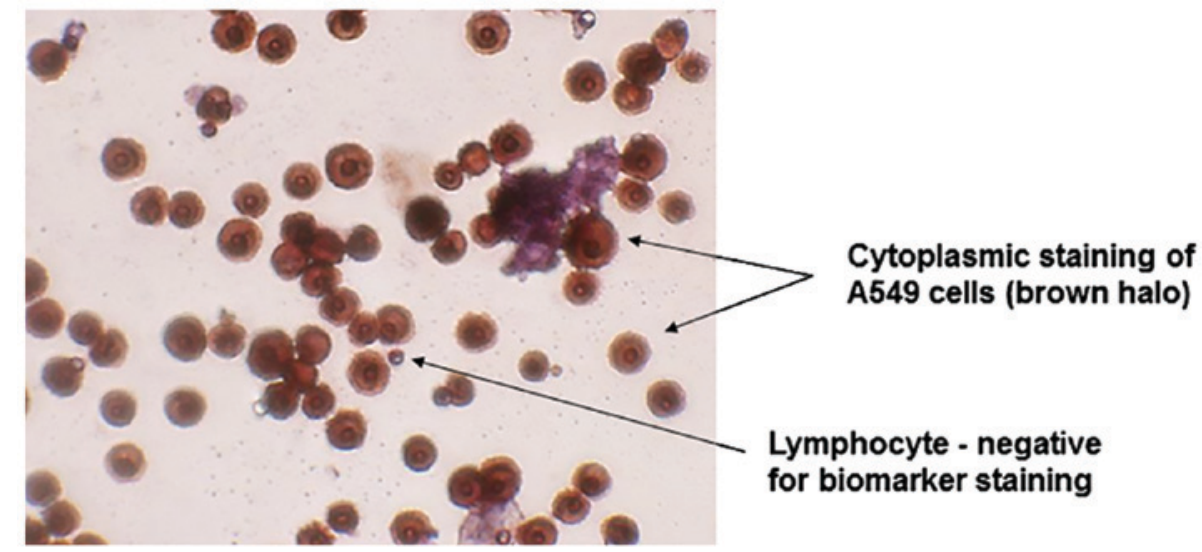

Figure 2. Microscopy image of AE1/3-stained A549 cells (magnification, x40). There was strong positive cytoplasmic staining of AE1/3 in the A549 cells shown by the deep brown halo around the cells. Lymphocytes were used as a negative control.

\section{Results}

Screening for lung carcinoma cells with the ScreenCell ${ }^{\circledR}$ filtration device. In order to validate the ScreenCell ${ }^{\circledR}$ filtration device, A549 human lung carcinoma cells were utilised, as this cell line tests positive for AE1/3. The results of this experiment identified a strong positive AE1/3 cytoplasmic staining of inoculated A549 cells, whereas lymphocytes were negative for AE1/3 staining and markedly smaller in size (Fig. 2).

Isolation of CTCs from the blood samples of patients with lung cancer. Using the ScreenCell ${ }^{\circledR}$ filtration device, CTCs were detected in $80 \%$ of the initial peripheral preoperative blood samples and $100 \%$ of the central pulmonary vein blood samples taken from the tumour-bearing lobe prior to division (Table I). There was a significant increase $(\mathrm{P}=0.04)$ in the volume of CTCs between the baseline and preligation sampling (Fig. 3). Occurring in the majority of patients tested, this finding supports the hypothesis that the surgical manipulation of the lung, and therefore primary tumour, results in an increased CTC concentration in the blood. Following resection, however, this volume quickly returned to a level close to the baseline, with a range similar to that detected preoperatively (Fig. 3). There was no significant change in the volume of CTCs between baseline levels and either initial post-surgery concentrations $(\mathrm{P}=0.99)$ or those three days postoperatively $(\mathrm{P}=0.5)$. All ten patients, regardless of preoperative levels of CTCs, were observed to have tumour cells in their peripheral blood three days following resection. Eight patients were identified to have large clusters of CTCs ( $>5$ cells) in pulmonary vein blood samples following lung manipulation, with a further patient having smaller clusters. Five of these patients had no detectable clusters in their baseline sample (Fig. 4).

There was no significant difference between the mean number of CTCs detected in squamous cell carcinoma or adenocarcinoma $(\mathrm{P}=0.71)$ and no difference in the mean number of CTCs between current smokers, ex-smokers and non-smokers ( $\mathrm{P}=0.89)$ (data not shown). The number of CTCs 
Table I. Number of CTCs detected at each stage of the investigation.

Number of detected CTCs

Blood sample type

Mean, n

Range, $\mathrm{n}$

Patients, $\%$

Peripheral vessel prior to surgery

22.2

$0-100$

80

Pulmonary vein draining the tumour-bearing lobe prior to resection

65.1

$8-200$

Pulmonary vein following resection

19.4

$0-100$

80

Peripheral vessel 3 days post-resection

23.5

2-100

100

CTC, circulating tumour cell.

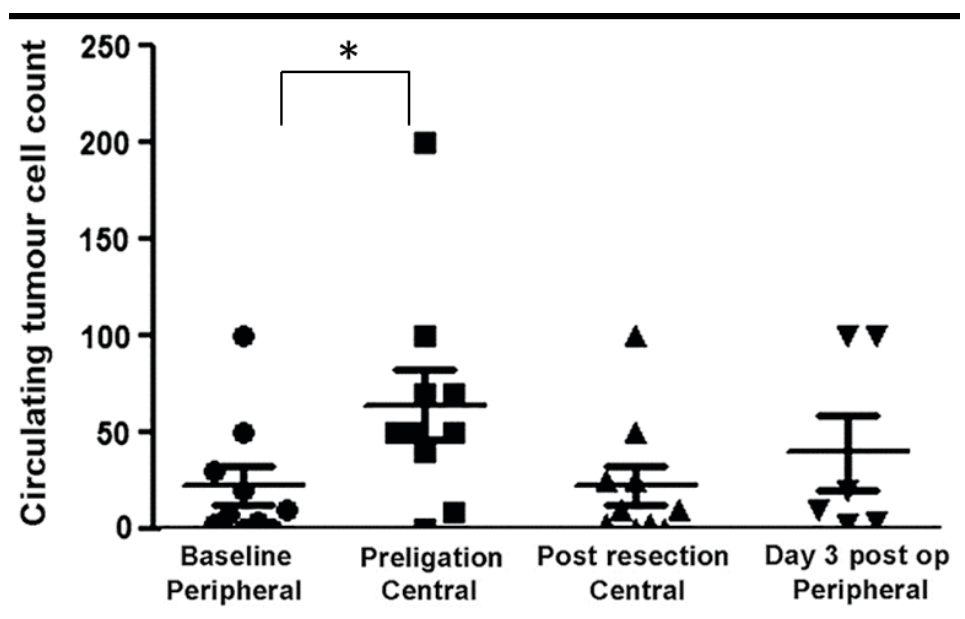

\section{Timing of blood sampling}

Figure 3. Number of circulating tumour cells at each stage of sampling in patients with lung cancer. ${ }^{*} \mathrm{P}=0.04$. Post op, postoperatively.
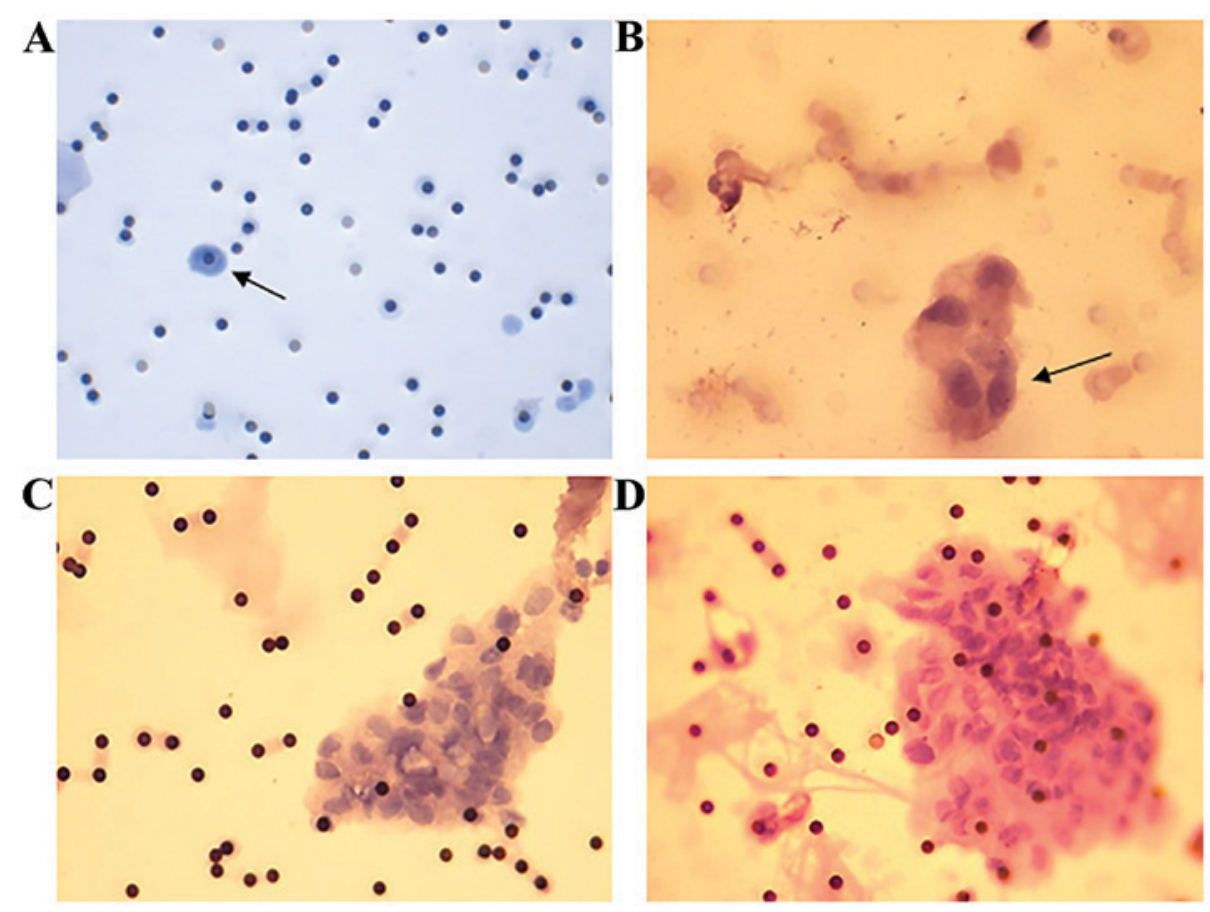

Figure 4. Positively haematoxylin and eosin-stained filters. (A) Stage IA (all staging as per TNM lung cancer staging classification) patient (magnification, $\mathrm{x} 20$ ), a single atypical suspicious cell is visible (black arrow). (B) Stage IIA patient (magnification, 40x), a small group ( 4) of atypical suspicious cells is visible (black arrow). (C) Stage IIB patient (magnification, $\mathrm{x} 40$ ), on the right side of the image a large cluster of atypical cells are visible (circulating tumour microemboli). (D) Stage III patient of a large cluster of circulating tumour cells are visible to the right of the image, with a distinctly larger nuclei:cytoplasmic ratio, characteristic of malignant cells. The dark black spots across the membrane represent pores on the filter (magnification, $\mathrm{x} 40$ ). 
collected at any stage of surgery had no correlation with the nodal status of the patient, tumour size or overall staging of the tumour (data not shown).

At the end of the study, nine patients were alive and disease-free. One patient succumbed to heart disease $>1$ year following the surgery. The same patient was identified to have a metastatic deposit of lung cancer in the femur prior to death. The post-resection pathological staging of this patient's adenocarcinoma of the lung was T2bN2 (stage IIIa), the highest stage of any of the studied patients. Looking specifically at this patient's CTC findings, despite having operatively confirmed $\mathrm{N} 2$ disease, his baseline CTC count was 0 cells $/ \mathrm{mm}^{3}$ (data not shown). This rose during lung manipulation to 40 cells $/ \mathrm{mm}^{3}$ at preligation, fell post-resection to 25 cells $/ \mathrm{mm}^{3}$. and the patient's final blood sample exhibited 3 cells $/ \mathrm{mm}^{3}$ (data not shown). Although not alone in the increase in CTC count from baseline during resection, this patient was one of only two patients who had no appreciable circulating tumour cells preoperatively. Despite a rise in CTC count, no significant association between the late development of distant metastatic deposits of the tumour and preoperative, intraoperative or postoperative concentrations of CTCs was observed in the present study.

\section{Discussion}

Metastatic spread is unpredictable and remains poorly understood. A well-described and researched area is that of tumour cell entry and movement in the general vasculature (2). Migrating tumour cells from the blood are commonly referred to as CTCs and have been heavily implicated in the development of metastases (8). The underlying mechanisms of tumour cell dispersion from the primary tumour are not fully understood; however, it has been speculated that even simple physical exertion may cause this dispersion (9). As observed in the current study, detectable levels of CTCs circulate at rest. To this end, the general consensus amongst surgeons is to divide the pulmonary vein during resection as an early treatment step.

Several early studies (10-12) indicated that tumour manipulation during surgical resection may contribute to tumour cell dispersion into the pulmonary vein, with increased volumes of CTCs detected in blood from the pulmonary vein of patients who had little or no baseline CTC count (10). However, this manipulation is typically essential to perform a resection. In a more recent study, which evaluated 42 patient samples, blood was collected from the tumour-draining pulmonary vein at the end of the surgical procedure and analysed for CTCs (13). The authors' concluded that the CTCs appeared to have been mobilised as a result of surgery and that this may allow their further dissemination (13). The current study supports this finding, with 5/10 patients demonstrating a rise in CTC count intraoperatively, with two of these patients previously having no detectable CTCs at baseline readings.

There was no statistically significant difference found in pre- and post-operative levels of lung CTCs, as evaluated using the ScreenCell ${ }^{\circledR}$ technique. This lack of increase in the concentration of CTCs may be due to the surgical technique not dislodging a significant volume of cells, the metastatic potential of lung cancer or the sensitivity of the ScreenCell ${ }^{\circledR}$ system. A recent study, utilising the CellSearch ${ }^{\circledR}$ method
(Janssen Diagnostics, LLC, South Raritan, NJ, USA) of cell detection, concluded that there was a significant increase in the CTC count of pulmonary vein blood following surgical manipulation of a tumour (14). These findings are supported by the results of the present study.

There are several commercially available systems that use a variety of techniques to identify CTCs. The present study used a size-based filtration system produced by $\mathrm{ScreenCell}^{\circledR}$, due to its simplicity, speed and the benefit that it eliminates any antibody bias that may be introduced by other techniques. Hou et al (15) identified a strong correlation between an increased CTC count and poor patient survival. The current study did not validate these findings for non-small cell lung carcinoma.

The investigation of CTCs is not isolated to lung cancer, with the technology being utilised in numerous cancer types. Breast cancer was one of the first types of cancer to be investigated. Multiple studies have found a correlation between a high baseline CTC concentration and poor progression-free survival (16-19). In addition, reducing the level of breast cancer CTCs detectable in the blood has been identified to be a good marker of response to treatment, a correlation also demonstrated in colorectal cancer (16-19). As demonstrated in numerous studies, a more advanced tumour stage has been associated with a higher CTC count in the peripheral blood (16-19). CTCs are detectable at an early tumour stages at varying levels, allowing the potential use of CTC analysis as a method for early diagnosis $(3,4)$.

In conclusion, although a significant rise in CTCs was detected between the initial sample of peripheral blood taken and the operative sample obtained prior to pulmonary vein ligation, it was not possible to identify an association between CTC count and distant metastatic spread of the tumour. To the best of our knowledge, no prior studies have investigated the impact of intraoperative dissemination of CTCs into the systemic vasculature, for either short-term inflammatory responses or long-term patient survival. Although an increase in CTC concentration was identified to have no clinical impact in the present study, no recommendation can be made at this stage. Future studies may study a larger cohort of patients, in order to better define the rate of sensitivity and specificity of using the ScreenCell ${ }^{\circledR}$ filtration device in patients with lung cancer. Moreover, the ScreenCell ${ }^{\circledR}$ filtration device has been used successfully for detection of CTCs for breast cancer, in addition to head and neck cancer. Therefore, future studies using the ScreenCell ${ }^{\circledR}$ filtration device may generate novel data on CTC isolation from a wide repertoire of cancer types.

\section{Acknowledgements}

The present study was supported by the Cryotherapy Research Charity (grant no. G0029).

\section{References}

1. Desitter I, Guerrouahen BS, Benali-Furet N, Wechsler J,Jänne PA, Kuang Y, Yanagita M, Wang L, Berkowitz JA, Distel RJ, et al: A new device for rapid isolation by size and characterization of rare circulating tumor cells. Anticancer Res 31: 427-441, 2011.

2. Fidler IJ: The pathogenesis of cancer metastasis: The 'seed and soil' hypothesis revisited. Nat Rev Cancer 3: 453-458, 2003. 
3. Delloye-Bourgeois C, Fitamant J, Paradisi A, Cappellen D, Douc-Rasy S, Raquin MA, Stupack D, Nakagawara A, Rousseau R, Combaret V, et al: Netrin-1 acts as a survival factor for aggressive neuroblastoma. J Exp Med 206: 833-847, 2009.

4. Nagrath S, Sequist LV, Maheswaran S, Bell DW, Irimia D, Ulkus L, Smith MR, Kwak EL, Digumarthy S, Muzikansky A, et al: Isolation of rare circulating tumour cells in cancer patients by microchip technology. Nature 450: 1235-1239, 2007.

5. Munzone E, Botteri E, Sandri MT, Esposito A, Adamoli L, Zorzino L, Sciandivasci A, Cassatella MC, Rotmensz N, Aurilio G, et al: Prognostic value of circulating tumor cells according to immunohistochemically defined molecular subtypes in advanced breast cancer. Clin Breast Cancer 12: 340-346, 2012

6. Zhang S, Lu Z, Unruh AK, Ivan C, Baggerly KA, Calin GA, Li Z, Bast RC Jr and Le XF: Clinically relevant microRNAs in ovarian cancer. Mol Cancer Res 13: 393-401, 2015.

7. Krebs MG, Hou JM, Sloane R, Lancashire L, Priest L, Nonaka D, Ward TH, Backen A, Clack G, Hughes A, et al: Analysis of circulating tumor cells in patients with non-small cell lung cancer using epithelial marker dependent and independent approaches. J Thorac Oncol 7: 306-315, 2012.

8. Hiltermann TJ, Pore MM, van den Berg A, Timens W, Boezen HM, Liesker JJ, Schouwink JH, Wijnands WJ, Kerner GS, Kruyt FA, et al: Circulating tumor cells in small-cell lung cancer: A predictive and prognostic factor. Ann Oncol 23: 2937-2942, 2012

9. Fidler IJ: Tumour heterogeneity and the biology of cancer invasion and metastasis. Cancer Res 38: 2651-2660, 1978.

10. Scheinin TM and Koivuniemi AP: The occurrence of cancer cells in blood. Surgery 51: 652-657, 1962.

11. Lee VW, Chiang T and Deodar SD: Bioassay for quantifying circulating tumour cells in a syngenic mouse model. Cancer Res 36: 2053-2058, 1976.

12. Karl A, Tritschler S, Hofmann S, Stief CG and Schindlbeck C: Perioperative search for circulating tumor cells in patients undergoing radical cystectomy for bladder cancer. Eur J Med Res 14: 487-490, 2009
13. Yao X, Williamson C, Adalsteinsson VA, D'Agostino RS, Fitton T, Smaroff GG, William RT, Wittrup KD and Love JC: Tumor cells are dislodged into the pulmonary vein during lobectomy. J Thorac Cardiovasc Surg 148: 3224-3231, 2014.

14. Hashimoto M, Tanaka F, Yoneda K, Takuwa T, Matsumoto S, Okumura Y, Kondo N, Tsubota N, Tsujimura T, Tabata C, et al: Significant increase in circulating tumour cells in pulmonary venous blood during surgical manipulation in patients with primary lung cancer. Interact Cardiovasc Thorac Surg 18: 775-783, 2014.

15. Hou JM, Greystoke A, Lancashire L, Cummings J, Ward T, Board R, Amir E, Hughes S, Krebs M, Hughes A, et al: Evaluation of circulating tumor cells and serological cell death biomarkers in small cell lung cancer patients undergoing chemotherapy. Am J Pathol 175: 808-816, 2009.

16. Hayes DF, Cristofanilli M, Budd GT, Ellis MJ, Stopeck A, Miller MC, Matera J, Allard WJ, Doyle GV and Terstappen LW: Circulating tumor cells at each follow-up time point during therapy of metastatic breast cancer patients predict progression-free and overall survival. Clin Cancer Res 12: 4218-4224, 2006.

17. Cristofanilli M, Hayes DF, Budd GT, Ellis MJ, Stopeck A, Reuben JM, Doyle GV, Matera J, Allard WJ, Miller MC, et al: Circulating tumor cells: A novel prognostic factor for newly diagnosed metastatic breast cancer. J Clin Oncol 23: 1420-1430, 2005.

18. Krebs MG, Hou JM, Ward TH, Blackhall FH and Dive C: Circulating tumour cells: Their utility in cancer management and predicting outcomes. Ther Adv Med Oncol 2: 351-365, 2010.

19. Cohen SJ, Punt CJ, Iannotti N, Saidman BH, Sabbath KD, Gabrail NY, Picus J, Morse M, Mitchell E, Miller MC, et al: Relationship of circulating tumor cells to tumor response, progression-free survival, and overall survival in patients with metastatic colorectal cancer. J Clin Oncol 26: 3213-3221, 2008 . 